Philippe Eggimann
Giorgio Zanetti

\section{On the way towards eradication of catheter-related infections!}

Received: 28 January 2008

Accepted: 28 January 2008

(C) Springer-Verlag 2008

This editorial refers to the article available at: http://dx.doi.org/10.1007/s00134-008-1046-3.

P. Eggimann · G. Zanetti

University Hospital (CHUV), Department of Intensive Care and Burn Center, Service of Hospital Preventive Medicine,

Lausanne, Switzerland

P. Eggimann (৫)

CH Universitaire Vaudois, Critical Care Medicine,

Bugnon 46, 1011 Lausanne, Switzerland

e-mail: philippe.eggimann@ hospvd.ch

The management of critically ill patients is virtually impossible without intravascular access devices, and about half of those used in intensive care units (ICUs) are central venous catheters (CVCs). Unfortunately, these devices are risk factors for bloodstream and other catheter-related infections $[1,2]$, the rates of which are used as markers for the quality of hospital care over time [3]. Most of these infections are indeed preventable and have progressively decreased over the past decade in the USA, from a pooled mean of 5.0 per 1,000 catheter-days for the 1992-2004 period to 2.9 in 2006 [4]. This may largely be due to education-based multimodal interventions, which were incorporated as a key recommendation in the prevention guidelines [5, 6]. Recent experience confirms the positive impact of such an approach and strongly suggests that the objective should now be to eradicate CVC-related infections $[7,8]$.

To achieve this goal, important points for which further evidence has been reported should now be translated into clinical practice. This is the case for skin disinfection, and for detailed protocols for insertion and care of CVCs that should now be standardized and further incorporated into daily clinical practice. The role of chlorhexidine should be highlighted. Skin disinfection with alcohol-based solutions of chlorhexidine may be superior to other agents, including alcohol-based iodine solutions [9, 10]. Chlorhexidineimpregnated dressings may prevent infections, but their impact should be further investigated [11]. Patient bathing with chlorhexidine washcloths was also recently reported to decrease catheter-related infections [12].

Another important component of prevention is surveillance [5]. Traditional methods based on manual review of clinical and microbiological data are time-consuming and may not be extended beyond research purposes [13, 14]. Recent data suggest that automated surveillance incorporating administrative parameters in an algorithm connected to electronic laboratory survey of bloodstream infections is accurate in clinical practice [15].

The results reported by Gowardman et al. in this issue [16] further stress the importance of careful insertion and care of CVCs. Their observational study of 605 shortterm CVCs consecutively inserted in a single Australian ICU confirms that devices inserted at the subclavian site are significantly less colonized and that those inserted in the emergency department are associated with a higher risk of contamination. Interestingly, they found that the risk was lower in female patients, particularly at the jugular site and for coagulase-negative staphylococci.

The rate of bloodstream infection was low and the study was therefore underpowered to detect differences in catheter-related infections. Optimal observance of potentially important measures included in the protocol for insertion and management of the devices may have contributed to this low rate of infection [5,9]. The absence of impact on the rate of infection is usually viewed as a limitation, but catheter-tip colonization may be considered as a surrogate for further infection [17]. 
The rates of catheter-related infection have decreased to levels for which power calculation implies that a sufficient number of CVCs could only be reached with a multicenter approach $[4,7]$. The design of such studies is, however, limited regarding infection control measures and detailed technique for catheter insertion and care. In contrast, data from prospective cohort studies performed in single institutions may allow detailed exploration of other aspects of clinical practice. This is the case in the study reported by Gowardman et al. [16]. One third of catheters were antiseptic-coated and were associated with a significant reduction of colonization at the jugular site. However, their use was not subject to a protocol, and the "rollplate" technique used for culture may have altered these results [16].

Randomized clinical studies and meta-analyses reported significant reduction of catheter-related infections with the use of antiseptic- and/or antimicrobial-coated catheters, but globally, the impact of these devices is in the same range as those of the educational programs [18]. However, only few prospective cohort studies evaluated the impact of such devices, which was at least limited for short-term catheterization and only in the case of high initial infection rates $[19,20]$. Accordingly, coated devices should not be viewed as magic bullets and until further evidence is furnished, guidelines and experts suggest their use only if other measures have failed to reduce or control catheter-related infections $[5,21]$. The pathophysiology of catheter-related infections includes a limited number of sources of infection. Infection originates from colonization of the outer surface of the device, itself contaminated by the skin flora during insertion or dressing care. Colonization of the inner surface through hub's contamination becomes predominant only after one week $[5,21]$.

Differences in structure and properties of the jugular skin between man and women may explain the differences in colonization rates reported by Gowardman et al. [16]. A higher number and density of hairs and follicles are potential sources of microorganisms almost impossible to eradicate with skin preparation. The continuous growth of hairs in combination with moisture resulting from sudation alters rapidly the efficacy of any dressing device with further increased opportunity for contamination. Prompt insertion of vascular access devices in patients with life-threatening conditions cannot be avoided in the emergency department, where optimal observance of preventive measures is difficult. However, true central venous access is rarely mandatory in the emergency department, and insertion of such devices should be postponed until transfer of the patient to the operation room or the ICU. Alternatively, as these higher risks of colonization can be neglected no longer, extension of the standardization of the insertion procedure should be extended to the emergency department when feasible.

To conclude, the data provided by Gowardman et al. further support the systematic use of the subclavian route for CVCs in critically ill patients, and postponement of their insertion until the transfer of the patient to the ICU or the operating room. This may lead to further progress along the road to eradication of catheter-related infections in critically ill patients.

\section{References}

1. Maki DG, Kluger DM, Crnich CJ (2006) The risk of bloodstream infection in adults with different intravascular devices: a systematic review of 200 published prospective studies. Mayo Clin Proc 81:1159-1171

2. Eggimann P (2007) Diagnosis of intravascular catheter infection. Curr Opin Infect Dis 20:353-359

3. Berwick DM, Calkins DR, McCannon CJ, Hackbarth AD (2006) The 100,000 lives campaign: setting a goal and a deadline for improving health care quality. JAMA 295:324-327

4. Edwards JR, Peterson KD, Andrus ML, Tolson JS, Goulding JS, Dudeck MA, Mincey RB, Pollock DA, Horan TC; NHSN Facilities (2007) National Healthcare Safety Network (NHSN) Report, data summary for 2006 , issued June 2007. Am J Infect Control 35:290-301
5. O'Grady NP, Alexander M, Dellinger EP, Gerberding JL, Heard SO, Maki DG, Masur H, McCormick RD, Mermel LA, Pearson ML, Raad II, Randolph A, Weinstein RA (2002) Guidelines for the prevention of intravascular catheter-related infections. Centers for Disease Control and Prevention. Morb Mortal Wkly Rep 51(RR-10):1-29

6. Eggimann P, Hugonnet S, Sax H, Harbarth S, Chevrolet JC, Pittet D (2005) Long-term reduction of vascular accessassociated bloodstream infection. Ann Intern Med 142:875-876

7. Pronovost P, Needham D, Berenholtz S, Sinopoli D, Chu H, Cosgrove S, Sexton B, Hyzy R, Welsh R, Roth G, Bander J, Kepros J, Goeschel C (2006) An intervention to decrease catheterrelated bloodstream infections in the ICU. N Engl J Med 355:2725-2732
8. Wenzel RP, Edmond MB (2006) Team-based prevention of catheterrelated infections. N Engl J Med 355:2781-2783

9. Chaiyakunapruk N, Veenstra DL, Lipsky BA, Saint S (2002) Chlorhexidine compared with povidone-iodine solution for vascular catheter-site care: a meta-analysis. Ann Intern Med 136:792-801

10. Mimoz O, Villeminey $S$, Ragot $S$, Dahyot-Fizelier C, Laksiri L, Petitpas F, Debaene B (2007) Chlorhexidine-based antiseptic solution vs alcohol-based povidone-iodine for central venous catheter care. Arch Intern Med 167:2066-2072

11. Ho KM, Litton E (2006) Use of chlorhexidine-impregnated dressing to prevent vascular and epidural catheter colonization and infection: a metaanalysis. J Antimicrob Chemother 58:281-287 
12. Bleasdale SC, Trick WE, Gonzalez IM, Lyles RD, Hayden MK, Weinstein RA (2007) Effectiveness of chlorhexidine bathing to reduce catheter-associated bloodstream infections in medical intensive care unit patients. Arch Intern Med 167:2073-2079

13. Eggimann P, Harbarth S, Constantin MN, Touveneau S, Chevrolet JC, Pittet D (2000) Impact of a prevention strategy targeted at vascular-access care on incidence of infections acquired in intensive care. Lancet 355:1864-1868

14. Trick WE, Zagorski BM, Tokars JI, Vernon MO, Welbel SF, Wisniewski MF, Richards C, Weinstein RA (2004) Computer algorithms to detect bloodstream infections. Emerg Infect Dis 10:1612-1620
15. Bellini C, Petignat $C$, Francioli $P$, Wenger A, Bille J, Klopotov A, Vallet Y, Patthey R, Zanetti G (2007) Comparison of automated strategies for surveillance of nosocomial bacteremia. Infect Control Hosp Epidemiol 28:1030-1035

16. Gowardman J (2008) Influence of insertion site on central venous catheter (CVC) colonization and bloodstream infection rates. Intensive Care Med DOI 10.1007/s00134-008-1046-3

17. Mermel LA, McCormick RD, Springman SR, Maki DG (1991) The pathogenesis and epidemiology of catheter-related infection with pulmonary artery Swan-Ganz catheters: a prospective study utilizing molecular subtyping. Am J Med 91:197S-205S

18. Eggimann P (2007) Prevention of intravascular catheter infection. Curr Opin Infect Dis 20:360-369
19. Schuerer DJ, Zack JE, Thomas J, Borecki IB, Sona CS, Schallom ME, Venker M, Nemeth JL, Ward MR, Verjan L, Warren DK, Fraser VJ, Mazuski JE, Boyle WA, Buchman TG, Coopersmith CM (2007) Effect of chlorhexidine/silver sulfadiazineimpregnated central venous catheters in an intensive care unit with a low blood stream infection rate after implementation of an educational program: a before-after trial. Surg Infect (Larchmt) 8:445-454

20. Niel-Weise BS, Stijnen T, van den Broek PJ (2007) Anti-infective-treated central venous catheters: a systematic review of randomized controlled trials. Intensive Care Med 33:2058-2068

21. Timsit JF (2005) [Updating of the 12th consensus conference of the Societe de Reanimation de langue francaise (SRLF): catheter related infections in the intensive care unit]. Ann Fr Anesth Reanim 24:315-322 